\title{
Magnetic Nanocomposite Thin Films Prepared by Sol-Gel Process
}

\author{
Nelcy D. S. Mohallem*, Luciana M. Seara*, Miguel A. Novak ${ }^{\dagger}$, and Elis H. C. P. Sinnecker ${ }^{\dagger}$ \\ *Laboratório de Materiais Nanoestruturados, DQ, UFMG, 31270-901, Belo Horizonte - MG, Brazil \\ $\dagger$ Instituto de Física, UFRJ - Rio de Janeiro, RJ, Brazil
}

Received on 8 December, 2005

\begin{abstract}
Cobalt ferrite composite thin films, $\mathrm{CoFe}_{2} \mathrm{O}_{4} / \mathrm{SiO}_{2}$, were prepared by sol-gel process, using tetraethylorthosilicate (TEOS) as a precursor for silica, and metallic nitrates as precursors for ferrite. The obtained dip-coated films thermally treated at 550,750, and $950{ }^{\circ} \mathrm{C}$ were transparent, homogeneous and adherent. Their magnetic properties were measured from $2.5 \mathrm{~K}$ to $300 \mathrm{~K}$ using a SQUID magnetometer. Superparamagnetic behaviour was observed at room temperature and below a blocking temperature appears with coercivity values increasing with annealing temperature.
\end{abstract}

Keywords: Magnetic thin films; Sol-gel process; Magnetic nanocomposite

\section{INTRODUCTION}

Nanocomposite materials formed by metallic or oxide particles dispersed in polymer, ceramic or vitreous matrices [1] have important application in areas such as catalysis and electronics [2]. An interesting class of nanocomposite materials is formed by nanometer sized magnetic particles dispersed in insulating matrix [3]. These nanocrystalline particles have a high surface/volume ratio, leading to magnetic properties different from those of bulk materials. Such properties are also highly dependent on the particle size distribution as well as on the aggregation of particles when compared to different production methods.

Sol-gel process has proved to be an efficient method to prepare ultra-fine particles dispersed in different matrices and, particularly, to produce thin film. Through this method, a good control of the sample morphology, texture, structure, and chemical composition can be attained by carefully monitoring the preparation parameters [4-8]. The use of an inorganic matrix allows narrow dispersion of particle size, and homogeneous distribution.

In this report, we show the morphological, structural and magnetic studies of $\mathrm{CoFe}_{2} \mathrm{O}_{4} / \mathrm{SiO}_{2}$ thin films prepared by solgel process as a function of different thermal treatment temperature.

\section{EXPERIMENTAL}

$\mathrm{CoFe}_{2} \mathrm{O}_{4} / \mathrm{SiO}_{2}$ nanocomposite thin films were prepared by sol- gel process using a precursor solution obtained from the mixture of tetraethylorthosilicate (TEOS; Merck), ethyl alcohol, water, $\mathrm{Co}\left(\mathrm{NO}_{3}\right)_{2} \cdot 6 \mathrm{H}_{2} \mathrm{O}$ and $\mathrm{Fe}\left(\mathrm{NO}_{3}\right)_{2} .9 \mathrm{H}_{2} \mathrm{O}$ (Carlo Erba). The films were prepared with 30 wt.\% of ferrite dispersed in the silica matrix. The precursor solution was stirred for $1 \mathrm{~h}$ for homogenization and rested until the viscosity reached the best value condition $(2-5 \mathrm{cp})$ for the dipcoating process. The films were prepared onto clean quartz substrates using withdrawal speed of $0.6 \mathrm{~mm} / \mathrm{s}$. After the coating process, the samples were dried in air at ambient temperature $\left(\sim 25^{\circ} \mathrm{C}\right)$ for $24 \mathrm{~h}$, dried at $80^{\circ} \mathrm{C}$ for $1 \mathrm{~h}$ and finally treated at 550,750 , and $950^{\circ} \mathrm{C}$ for 10 minutes.
Thicknesses were measured by profilometry with a Alphastep 100 profilometer, Tencor Instruments, with an estimated $6 \%$ uncertainty. The transparency of the films was determined by optical transmission spectra measured with an ultraviolet and visible spectrometer (U3010, Hitachi).

Film porosity and topography were investigated by atomic force microscopy (LNLS) using a Nanoscope III from Digital Instruments, equipped with an extended modulus for phase imaging. The images were generated through the intermittent contact mode, using a silicon probe tip with $5 \mathrm{~nm}$ of curvature radius.

The evolution of the crystallinity structure and nanoparticule size with the thermal treatment temperature were observed by low angle X-ray diffractometry (incidence angle of $5^{\circ}$ ) at the D12A-XRD1 beam of the Laboratorio Nacional de Luz Sincrotron using radiation of $1.5424 \AA$.

Magnetization measurements of the composite films as function of field and temperature were performed using a Cryogenic SX-600 SQUID magnetometer between 2 and $300 \mathrm{~K}$, up to $6 \mathrm{~T}$.

\section{RESULTS AND DISCUSSION}

The films obtained were transparent, adherent, and free of cracks. All samples presented layers with thickness (500 \pm 40) $\mathrm{nm}$ when treated at $550{ }^{\circ} \mathrm{C}$ and $(400 \pm 30) \mathrm{nm}$ when treated at $950{ }^{\circ} \mathrm{C}$. The optical transmission of the films in the visible region increases with increasing treatment temperature showing maximum transmittance at $900 \mathrm{~nm}$ of $84 \%$ for the film treated at $550^{\circ} \mathrm{C}$ and $91 \%$ for the one treated at $950{ }^{\circ} \mathrm{C}$. At $500 \mathrm{~nm}$ the transparency decreases due to the film absorption in this range.

The X-ray peaks of the composite film (shown in Fig. 1) are in accordance with those of a typical crystalline Co ferrite, with spinel structure without a preferred orientation. The peak intensities increase with increasing the thermal treatment temperature. No peaks associated to quartz, crystobalite or intermediary products were found. The crystallite sizes of the ferrite dispersed in the matrix were estimated from DebyeScherrer's formula and were found to be between $(5 \pm 2)$ and $(20 \pm 5) \mathrm{nm}$ for samples heated between 550 and $950^{\circ} \mathrm{C}$. 


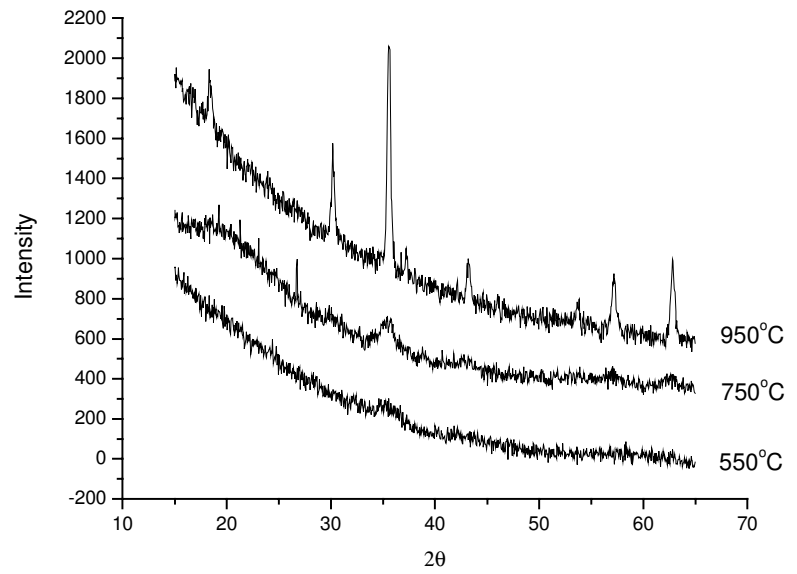

FIG. 1: Diffractogram of Co ferrite composite thin films heat treated at 550,750 and $950{ }^{\circ} \mathrm{C}$.

AFM analysis showed characteristic images of the films treated at $550^{\circ} \mathrm{C}$ (Figure 2) with porous surfaces typical of xerogel structures. With the increase in the thermal treatment temperature particles with nearly spherical shape (see Fig. 3) became apparent. It is not possible to distinguish the ferrite particles from the silica matrix, but we believe that the silica encapsulated the ferrite nanoparticles. The particle size increased with the increase in the heat treatment temperature while the rugosity decreased.

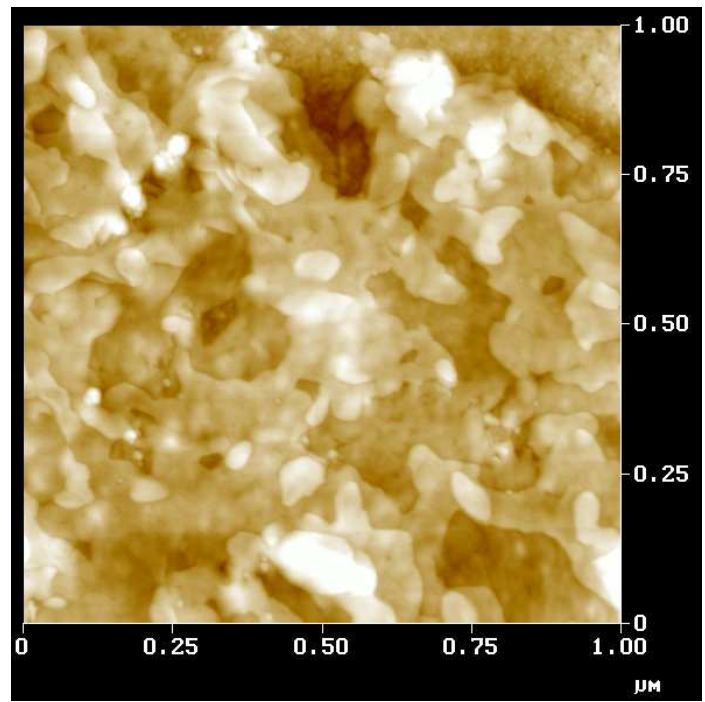

FIG. 2: AFM image of $\mathrm{CoFe}_{2} \mathrm{O}_{4} / \mathrm{SiO}_{2}$ thin film treated at $550{ }^{\circ} \mathrm{C}$.

Magnetization measurements done in the plane direction of the films showed typical superparamagnetic behavior at room temperature for the samples treated at $750{ }^{\circ} \mathrm{C}$ (see Fig. 4) and $950^{\circ} \mathrm{C}$, and almost no signal for the sample treated at $550^{\circ} \mathrm{C}$. This indicates that the ferrite nanoparticles are formed above this temperature. At low temperature hysteresis develops below $100 \mathrm{~K}$ becoming quite wide at $10 \mathrm{~K}$ with coercivity of $1.2 \mathrm{~T}$. This behavior can be associated to the blocking of the superparamagnetic particle dynamics. In fact, zero field cooled

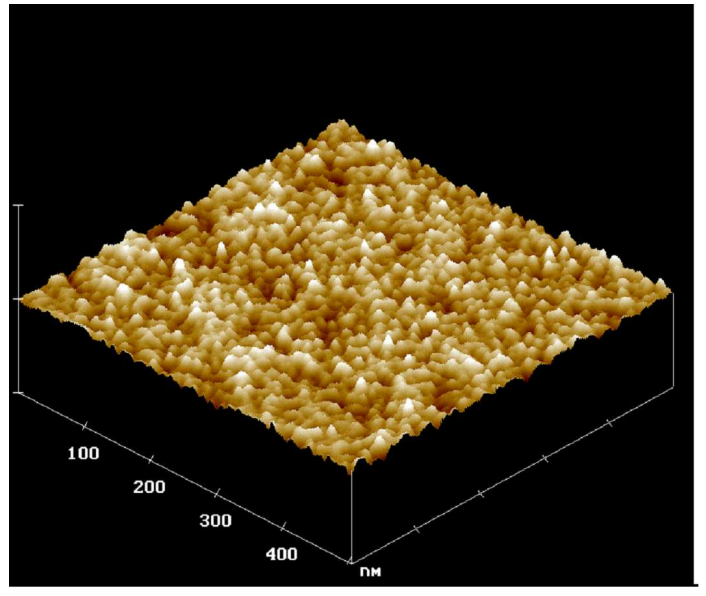

FIG. 3: AFM image of $\mathrm{CoFe}_{2} \mathrm{O}_{4} / \mathrm{SiO}_{2}$ thin film treated at $950{ }^{\circ} \mathrm{C}$.

(ZFC) as well as field cooled (FC) magnetization measurement were made as a function of temperature showing a maximum at $67 \mathrm{~K}$ for the sample treated at $750{ }^{\circ} \mathrm{C}$ (see Fig. 5). This maximum increased to $210 \mathrm{~K}$ for the sample treated at $950^{\circ} \mathrm{C}$ (not shown), which is in agreement with the coarsening of the magnetic nanoparticle sizes.

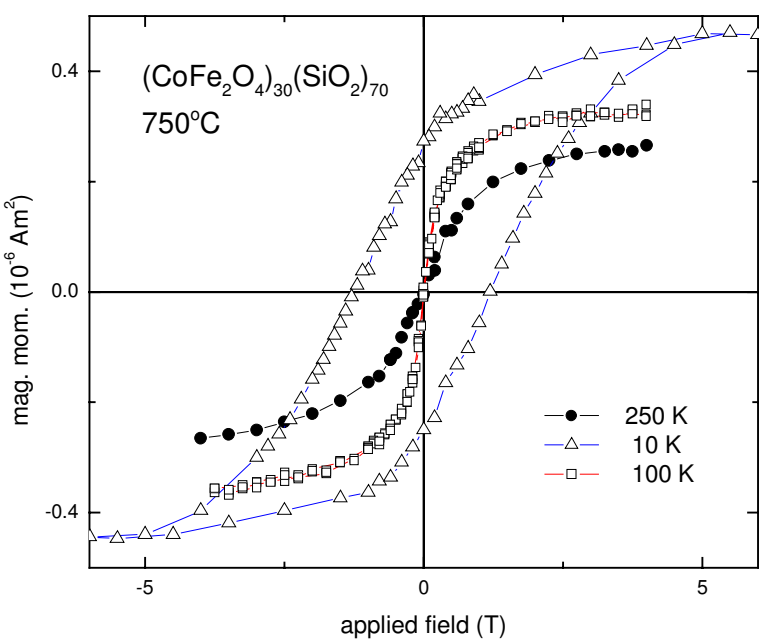

FIG. 4: Total magnetic moment of the sample treated at $750{ }^{\circ} \mathrm{C}$, measured at 3 different temperatures.

\section{CONCLUSION}

Transparent, homogeneous and adherent thin films formed by crystalline nanoparticle cobalt ferrite dispersed in silica matrix were successfully produced by sol-gel process. Thermal treatments were carried out at temperatures as high as $950^{\circ} \mathrm{C}$, without cracking, allowed to modify the surface morphology. The thickness of the films varied from 500 to 400 $\mathrm{nm}$ with higher treating temperatures. The atomic force microscopy showed that the films presented a porous homoge- 


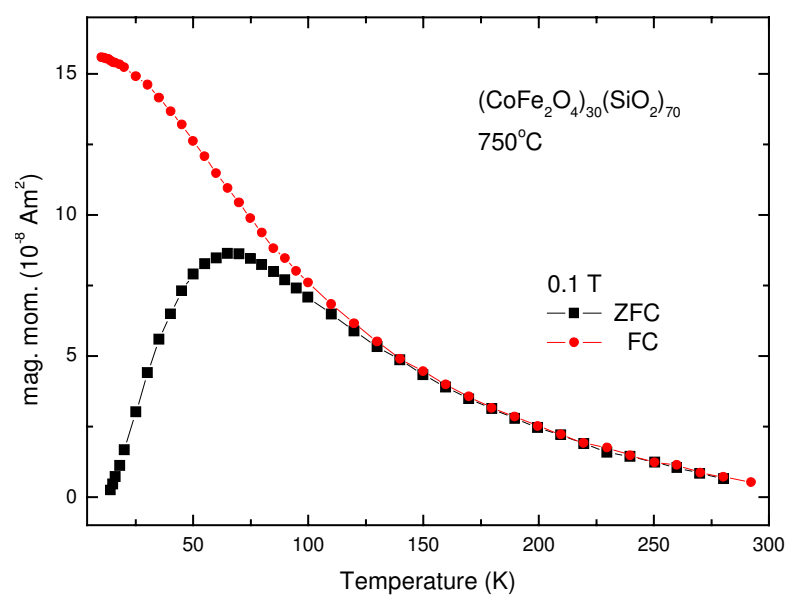

FIG. 5: Zero field cooled (squares) and field cooled (circles) magnetic moment of the sample of Fig. 4, at 0.1T. neous topography, changing to nanoparticulate morphology with heat treatment above $550^{\circ} \mathrm{C}$, presenting Co ferrite particle sizes in the order of $20 \mathrm{~nm}$ at $950{ }^{\circ} \mathrm{C}$. The particle sizes increase with higher temperature heat treatment. Superparamagnetic behavior was observed at room temperature as well as hysteresis due to blocking of the magnetic dynamics at low temperature. We believe that this system allows the control growth of silica coated magnetic nanoparticles with different sizes and distances among them. Further studies in these systems are in progress.

\section{Acknowledgements}

This work was supported by CNPq and LNLS (AFM and low angle XRD analyses).
[1] G. Ennas, A. Mei, A. Musinu, G. Piccaluga, G. Pinna, and S. Solinas, J. of Non Cryst. Solids 232-234, 587 (1998).

[2] C. Estournès, T. Lutz, J. Happich, T. Quaranta, P. Wissler, and J. L. Guille, J. Magn. Magn. Mater. 173, 83 (1997).

[3] L. Armelao, G. Granozzi, E. Tondello, P. Colombo, G. Principi, P. P. Lottici, and G. Antonioli, J. Non-Cryst. Solids 192\&193, 435 (1995).

[4] L. Zhang, G. C. Papaefthymiou, R. F. Ziolo, and J. Y. Ying,
Nanostructured Materials 9, 185 (1997).

[5] C. Yan, F. Cheng, C. Liao, J. Kuang, Z. Xu, L. Chen, H. Zhao, Z. Liu, Y. Wang, T. Zhu, and G. He, J. Magn. Magn. Mater. 192, 396 (1999).

[6] C. J. Brinker (Ed.), The Physics and Chemistry of Sol-Gel Processing, Academic Press, San Diego, 1990.

[7] N. D. S. Mohallem, L. M. Seara, App. Surf. Sci. 214, 143 (2003). 